\title{
Bases de dados de informação para negócios no Brasil
}

\section{Beatriz Valadares Cendón}

Professora adjunta - Escola de Ciência da I nformação - U niversidade F ederal de Minas Gerais.

E-mail: cendon@eci.ufmg.br

\section{Resumo}

Não existe atualmente uma publicação que compile e caracterize as fontes brasileiras de informação para negócios. O estudo aqui relatado contribuiu para o melhor conhecimento dessas fontes, identificando, selecionando, descrevendo, compilando e avaliando bases de dados brasileiras nas áreas de informações jurídicas, financeiras, sobre empresas e produtos, estatísticas e indicadores econômicos, oportunidades de negócios, vocabulário, investimento, biográficas, bem como bases de dados bibliográficas em temas como administração e economia. As descrições das bases de dados identificadas no projeto estão disponibilizadas no URL: http://www.eci.ufmg.br/cendon/ pesquisa.htm. Este artigo oferece uma visão geral das bases identificadas, narra a metodologia utilizada para seu levantamento $e$ descrição e analisa o conjunto das fontes de informação obtidas e de seus produtores.

Palavras-chave

Informação para negócios; Bases de dados.

\section{Brazilian business databases}

\begin{abstract}
Presently, there is not a publication that compiles and characterizes the Brazilian information sources for business. The study, here reported, has contributed for a better knowledge of these sources, identifying, selecting, describing, compiling and evaluating Brazilian databases in the areas of juridical and financial information about enterprises and products, statistics and economic indicators, business opportunities, vocabulary, investment, as well as bibliographic databases about themes related to administration and economy. The descriptions of the databases identified in the project are available on URL http://www.eci.ufmg.br/ cendon/pesquisa.htm. This paper offers an overall view of the databases identified, descrives the methodology utilized for the survey and description thereof and analyzes all the sources of the information obtained and its producers.
\end{abstract}

Keywords

Information for business; Databases.

\section{INTRO D U ÇÃO}

Em outros países, as fontes de informação para negócios ${ }^{* *}$ têm sido produzidas e organizadas desde 0 século passado, sendo rotineiramente fornecidas aos usuários por bibliotecas e outras organizações (Figueiredo, 1994; Lavin, 1992). No Brasil, entretanto, a consciência da necessidade da organização e do controle desse tipo de informações érecente. Convencionalmente chamada de "business information" nos Estados U nidos e Inglaterra, o termo "informação para negócios" só recentemente aparece na literatura brasileira ( $M$ ontalli, 1994; Figueiredo, 1994). Os poucos trabalhos publicados a respeito no meio acadêmico (Cendón, 2002; D uarte, 2000; Januzzi \& M ontalli, 1999; Souza \& Borges, 1999; Borges \& Campello, 1997; Souza \& Borges, 1996; Barbosa, 1994; Figueiredo, 1994; M ontalli, 1994; Barreto, 1996; Souza \& Borges, 1994; Barreto, 1991) caracterizam a falta deconhecimento sobre os produtores das fontes, sobre as fontes em si (sua qualidade, forma de acesso, organização, volume produzido), sobre os produtose serviços de informação que possam suprir sua demanda e mesmo sobre a necessidade de informações dos empresários brasileiros. A citação a seguir exemplifica esse desconhecimento:

"Q uem produz informação sobre mercado no Brasil? $O$ que produz a fundação IBG E, a fundação Seade? 0 que é de interesse para as empresas? Q uais são as características dos produtos fabricados pelas empresas

\footnotetext{
A autora agradece o apoio recebido da Fundação de $A$ mparo à Pesquisa do Estado de $M$ inas $G$ erais ( $F$ apemig).

** O termo "informação para negócios" éusado para designar o conjunto de informações usadas pelos administradores na redução de incertezas. Engloba, por exemplo, informações mercadológicas (tais como análises de fatias de mercado, padrões de consumo e gastos de consumidores, e estudos de seus comportamento e estilos de vida, pesquisas de opinião, informação sobre investimento em propaganda por diversos setores e medidas de audiência de canais de rádio e televisão); informações financeiras (tais como desempenho financeiro de empresas, mercado financeiro e outras informações para investimento, disponibilidade de assistência financeira, taxas de câmbio, custo de crédito etc.); informaçõesestatísticas (tais como recenseamentos, índices econômicos ou estatísticas sobre indústrias); informações sobre empresas e produtos ( tais como histórico einformações cadastrais de empresas e informações sobre fusões e aquisições); informações jurídicas (tais como leis, regulamentação de impostos e taxações) e outras informações fatuais e analíticas sobre tendências nos cenários político-social, econômico e financeiro, nos quais operam organizações empresariais ( Souza \& Borges, 1996; Souza, 1996; M ontalli, 1994).
} 


\section{Beatriz Valadares C endón}

do Pólos Tecnológicos de Santa Rita do Sapucaí...? Q ual foi o faturamento, quem compõe o staff das companhias X ou Y?" (M ontalli, 1994, p.166)

Segundo M ontalli, no Brasil, não existem meios bem definidos para responder a esse tipo de pergunta. $\mathrm{Na}$ falta de formalização desse setor de informações, empresários se valem primordialmente de fontes informais, as quais às vezes não são confiáveis e podem levar à tomada de decisões inadequadas (Pinto, 1994).

U m ponto de partida para se iniciar a organização do conhecimento sobrea área de informação para negócios no Brasil é a identificação das fontes existentes. N ão existe atualmente uma publicação que compile e caracterize as fontes brasileiras de informação para negócios. 0 estudo aqui relatado contribuiu para o melhor conhecimento dessas, identificando, selecionando, descrevendo, compilando e avaliando fontes brasileiras de informação de interesse para negócios. M ais especificamente, o projeto se concentrou nas bases de dados de informação para negócios, já que essas, por serem mais recentes, são particularmente carentes de documentação. No entanto, trabalhos anteriores evidenciaram a existência e uso dessas bases: a pesquisa realizada por Souza \& Borges (1996) em instituições fornecedoras de informação com potencial para negócios identificou que elas estavam dando ênfase ao desenvolvimento de bases de dados e que 0 acesso a elas constituía um dos serviços percentualmente mais oferecidos aos seus clientes por essas instituições. Borges \& Carvalho (1998) mostram também que $30 \%$ dessas instituições utilizam bases de dados próprias como fonte de informação para desenvolvimento deserviços voltados para negócios. M ais informações sobre essas bases de dados - quais são elas, qual o seu conteúdo, preço, forma de acesso edistribuição - não seencontram compiladas.

0 projeto, descrito a seguir, teve como objetivo levantar informações sobre bases de dados brasileiras nas áreas jurídica e financeira, sobre empresas e produtos, de estatísticas eindicadores econômicos, oportunidades de negócios, vocabulário, investimento, biográficas ebases de dados bibliográficas em área de interesse para negócios, como administração eeconomia. As descrições das bases de dados identificadas no projeto estão disponibilizadas no URL: http:// www.eci.ufmg.br/ cendon/pesquisa.htm. Este artigo narra a metodologia utilizada para levantamento e descrição das bases de dados e analisa o conjunto das fontes de informação obtidas e de seus produtores.

\section{METODOLOGIA}

Resumidamente, a metodologia para coleta de dados sobre as bases consistiu dos seguintes passos:

1. criação de lista inicial de potenciais produtores de bases de dados com base em revisão de literatura eoutras fontes pessoais;

2. pesquisa na Internet para identificação dos sites das instituições listadas no passo um;

3. varredura do site das instituições à procura de (a) bases de dados por elas produzidas e coleta inicial de dados sobre as bases; (b) indicações de outras instituições que potencialmente poderiam estar produzindo bases de dados ou de outras bases de dados de informação para negócios;

4. coleta de dados sobre as bases mediante 0 preenchimento de um formulário (descrito a seguir);

5. tentativa de confirmação e complementação dos dados obtidos na Internet mediante contato direto, por e-mail, com a instituição produtora;

6. inclusão das outras instituições encontradas na lista depotenciais produtores de bases de dados para posterior visita aos seus sites, repetindo para cada uma delas os passos de 2 a 6 ;

7. criação do guia de bases de dados.

A seguir, apresenta-se uma exposição detalhada do processo de busca das informações visando ao compartilhamento da experiência, das decisões tomadas e das dificuldades encontradas.

Definição da estratégia de busca e coleta de dados - U ma característica deste projeto foi o uso da Internet como principal fonte de informação. Supôs-se que as instituições que fornecem bases de dados como um produto de informação proveriam descrições das mesmas em seus sites e que, por meio de pesquisas na Internet, seriam obtidos mais dados do quepor meio do envio de questionários a uma lista predefinida de instituições. H ouve um processo de experimentação e de tentativa e erro atéa definição da estratégia de busca que melhor funcionaria.

Realizou-se, inicialmente, uma pesquisa em motores de busca com palavras-chave como "bases de dados" combinadas com termos que representavam uma área 
de conhecimento, por exemplo, "financeiras", "estatísticas" eoutras. Exceto para a área de informação jurídica, como será posteriormente comentado, essa pesquisa revelou-se pouco produtiva. A exploração de diretórios nacionais como o Cadê também não se mostrou profícua para identificar bases de dados de informações para negócios. Em vista desse resultado, adotou-se a estratégia de buscar as bases de dados por meio desites de instituições que poderiam ser potenciais produtores de bases de dados, como, por exemplo, editoras e diversos órgãos do governo ou da iniciativa privada. A compilação dessa lista inicial de potenciais produtores foi feita mediante revisão da escassa literatura sobre informação para negócios publicada nas revistas acadêmicas de ciência da informação, conversas com colegas everificação de jornais erevistas. Como resultado destetrabalho, obteve-se uma lista deinstituições ebases de dados que foi o ponto de partida para a pesquisa.

U ma pesquisa tendo por palavra-chave os nomes dos produtores ou das bases de dados revelava o U RLS das instituições produtoras. $N$ esta fase, foram utilizados principalmente os motores de busca Altavista, G oogle eTodobr. I niciavam-se então a visita e a exploração desses sites à procura de bases de dados ou da indicação, através dos serviços oferecidos, da existência de bases de dados internas que provavelmente eram usadas para produção desses serviços. N esta fase, links, tais como "Produtos e Serviços", eram especialmente visados. Os sites eram também explorados para a verificação de existência de links para outros prováveis produtores de informação para negócios, os quais eram, então, acrescentados à lista inicial de potenciais produtores para posterior visitação.

$\mathrm{N}$ a área jurídica, a mais rica em informações eletrônicas, além da estratégia descrita anteriormente, funcionou a pesquisa direta nos motores de busca com palavras-chave tais como "informação jurídica", ou "bases de dados jurídicas", ou "links jurídicos". Além dessa técnica, mostrou-se produtiva a exploração de portais jurídicos como o do Jus $N$ avegandi e o site da $O A B$, que contêm extensas compilações de recursos.

A estratégia final de busca e coleta de dados consistiu, portanto, da combinação de (1) pesquisa em fontes tradicionais de informação para identificar instituições produtoras, (2) pesquisa direta em motores de busca seguida de (3) navegação e exploração desites.

Ci. Inf., Brasília, v. 32, n. 2, p. 17-36, maio/ago. 2003
E laboração do formulário de descrição das bases de dados - As informações disponibilizadas na I nternet sobreas bases de dados eram muito variadas em formato e conteúdo, tornando necessária a definição de um formulário padrão para coleta de dados. Para uma decisão inicial sobre as informações que seriam coletadas, utilizou-se um diretório tradicional de bases de dados, 0 $G$ aleD irectory of $D$ atabases. D eterminou-setambém que informações seriam ignoradas. Por exemplo: optou-se por não se coletarem informações sobre recursos de busca oferecidos pelo sistema, campos específicos dos registros da base ou informações sobre o softwareutilizado para acesso à base.

Para fins de padronização de uma variedade de formatos de dados, estabeleceu-se um vocabulário controlado para alguns campos. Por exemplo, no campo "Forma de disponibilização", foram estabelecidos valores, tais como disquete, intranet, CD-RO M etc. Já para o campo “Tempo de cobertura", estabeleceu-se que ele poderia conter as datas de início e término dos dados-base ou o termo "variado", quando um CD-ROM contivesse uma variedade de bases de dados. Os valores possíveis para esses campos foram determinados ao longo da pesquisa à medida que as informações eram coletadas.

Ao longo do desenvolvimento do projeto, notou-se que seria interessante a inclusão de novos campos não previstos inicialmente, como caracterização do produtor, serviços de informação oferecidos fundamentados nas bases de dados, fonte da informação sobre os dados e data de coleta dos dados. Entretanto, por terem sido definidos a posteriori, incluíram-se estas informações na descrição de poucas das bases. A versão final do formulário continha os seguintes itens:

\section{1 - N ome da base de dados.}

2 - Conteúdo: breve descrição do conteúdo da base de dados incluindo seu escopo e cobertura.

3 - Produtor: nomee endereço completo para contato.

4 - Caracterização do produtor: este campo usou um vocabulário controlado para refletir o tipo do produtor (público ou privado) e objetivo da atividade (lucrativo ou não lucrativo).

5 - Aquisição: nome e endereço da instituição que disponibiliza a base de dados (que pode ou não ser a mesma que o produtor). 
6 - Início da produção: data do início da produção da base de dados em forma eletrônica.

7 - Forma de disponibilização: meio de disponibilização da base de dados, por exemplo, CD ROM , Internet ( neste campo usou-se um vocabulário controlado, descrito adiante);

8 - N úmero de registros: quantidade de registros na base de dados (por exemplos: número de registros bibliográficos, número de empresas ou produtos cadastrados).

9 - Tipo da base de dados: tipo de informação contida na base de dados, por exemplo: bibliográfica, estatística etc. (neste campo usou-se um vocabulário controlado, descrito adiante).

10 - Cobertura tópica: indica os assuntos que caracterizam o conteúdo, forma ou uso potencial da informação contida na base de dados, no nível de detalhe fornecido pelo produtor da base de dados. No caso dea base cobrir vários assuntos, usou-se um asterisco para indicar 0 assunto principal.

11 - Cobertura geográfica: indica a área geográfica para a qual a informação seaplica ou da qual foi derivada. N este campo, usou-se um vocabulário controlado com os seguintes termos: internacional, nacional, regional, estadual e municipal. Algumas bases de dados podem ter indicação demais deuma área de cobertura geográfica (por exemplo: internacional enacional).

12 - Tempo de cobertura: período coberto pelos dados na base. O s tipos possíveis são:

- Data de início - D ata de término:

- indica quea base dedados contém documentos datados no intervalo.

- Variada:

- indica que o CD -ROM contém um conjunto de bases dedados com tempo de cobertura variado.

13 - Freqüência de atualização: freqüência com que os dados da base são atualizados. N este campo usou-se vocabulário controlado que será descrito adiante.

14 - Serviços relacionados: serviços fornecidos pela organização produtora a partir da base de dados, como, por exemplo, relatórios ou outros tipos de publicação.
15 - 0 bservações: dados complementares sobre a base dedados fornecidos pelo produtor ou obtidos nal Internet.

16 - Fontes das informações sobre a base de dados: de onde emanam as informações obtidas sobre a base de dados. N este campo, usou-se um vocabulário controlado com os seguintes termos:

- Internet/Site do produtor - N ão confirmada:

- indica que as informações foram coletadas e/ ou inferidas do site do produtor. 0 produtor não respondeu ao e-mail deconfirmação dos dados.

- Internet/ site do produtor - Confirmada pelo produtor: - indica que as informações foram submetidas ao produtor por e-mail, sendo verificadas e confirmadas por ele.

16 - Data da coleta de dados: data em que as informações sobrea base de dados foram obtidas.

\section{Coleta de dados e descrição das bases de dados}

U ma vez definidas as informações a serem coletadas, exploraram-se os sites das instituições produtoras na Internet para se preencher o formulário descrito anteriormente, da forma mais completa possível, para cada base de dados. Muitas dificuldades foram encontradas, e decisões tiveram de ser tomadas para preenchimento do formulário. As bases de dados, na maioria das vezes, eram insuficientemente descritas. Às vezes, algumas informações não diretamente localizadas foram inferidas dos textos descritivos das bases obtidos nos sites. Por exemplo: podia-se muitas vezes deduzir-se que uma base era do tipo texto completo, embora isso não estivesseclaramente explicitado. O utras vezes, a partir da descrição, podia-sededuzir a cobertura tópica da base.

O utro problema surgiu com o uso de um formulário padrão para descrição de uma variedade detipos de bases de dados. $\mathrm{N}$ em todos os itens do formulário eram válidos para todos os tipos de bases. Tínhamos, por exemplo, bases de notícias, bases de séries estatísticas ou bases constituídas por um conjunto de arquivos contendo diversos textos de legislação no mesmo CD-ROM. Campos, como número de registros, não se aplicavam às bases de séries estatísticas e bases de coletâneas de textos de legislação. Já o campo cobertura geográfica não fazia sentido no caso de uma base de dicionário. 0 ptouse por não incluir na descrição os campos que não se aplicavam. 
O casionalmente, surgiram decisões difíceis sobre o que considerar como uma base de dados, pois nem sempre as fontes de informações encontradas se enquadravam perfeitamente no modelo tradicional de bases de dados estruturadas, constituídas de registros contendo campos padronizados. Por exemplo, freqüentemente no caso de informações jurídicas havia CD -RO M scom um conjunto de arquivos de texto completo de uma variedade de fontes. Entretanto, o CD-ROM possuía título único, como, por exemplo, Legislação Brasileira. O utras vezes era difícil determinar se certo produto deveria ser visto como base, serviço ou sistema de informação. Assim, foi necessária a definição de critérios para seleção. Para inclusão na lista, as bases de dados encontradas deveriam:

- ser produzidas no Brasil e ter, como foco principal, informações brasileiras;

- ter conteúdo tópico dentro de informações para negócios. As categorias iniciais foram informação jurídica, informação sobre empresas e produtos, informação financeira, informação estatística e oportunidades de negócios. Essa lista de categorias foi ajustada ao longo do projeto de acordo com as bases localizadas. Assim, foram posteriormente incluídas as categorias de bases de dados bibliográficas, de investimento, biográficas e vocabulário;

- conter uma coleção de registros, uniformemente estruturados em campos e pesquisáveis. Exceções foram, entretanto, abertas:

- no caso de bases de dados jurídicas, uma coletânea de arquivos com texto completo de diversas obras reunidas sob título único foi considerada uma base de dados;

- no caso de bases de dados estatísticas ( por exemplo, veja-se a base do (BGE), um conjunto de tabelas disponibilizadas via I nternet ou por outro meio, ainda que os dados não tivessem uma estrutura constante, foi considerada uma base dedados.

Os dados foram coletados no período entre 1999 e 2001.

\section{Confirmação dos dados}

Após o preenchimento inicial do formulário com os dados obtidos na Internet, o mesmo era enviado, acompanhado de carta de apresentação do projeto, via e mail, para o produtor da base de dados solicitando que o mesmo confirmasse as informações coletadas sobrea base e as corrigisse ou completasse quando preciso.
U m dos propósitos da coleta preliminar de dados na Internet era minimizar o trabalho do produtor para preenchimento do formulário e maximizar a probabilidade de retorno dos questionários preenchidos. Em algumas organizações de maior porte, houve problemas para se identificar o departamento ao qual o e-mail deveria ser dirigido. O utro problema relativamente freqüenteera o não-entendimento pelo respondente das informações solicitadas, apesar da descrição do conteúdo de cada campo.

N os casos em que o questionário não foi devolvido, procurou-se confirmar os dados via telefone. Por limitações de recursos para o projeto, esse procedimento ocorreu em poucos casos. Adicionalmente, na fase final do projeto, reenviou-se o e-mail inicial para todos os produtores que não haviam respondido ao anterior, na tentativa dese obter uma taxa mais alta de confirmações.

Ao final do projeto, enviou-secarta a todos os produtores de bases de dados representadas no site comunicando 0 endereço do sitee convidando-osa acrescentar ou corrigir dados sobre as bases de dados, caso necessário.

Produção do guia de bases de dados de informação para negócios. 0 conjunto de informações obtidas foi usado para elaborar uma descrição final das bases de dados. Eliminaram-se informações que não puderam ser inferidas ou confirmadas. A partir das informações obtidas, foi elaborado um site contendo todas as informações coletadas na pesquisa. Este site está disponibilizado para consulta na Internet com acesso ilimitado no U RL http:// www.eci.ufmg.br/ cendon/ pesquisa.htm.

\section{RESU LTAD O $S$}

O bteve-se um total de 134 bases de dados que se enquadram na área de informação para negócios, conforme mostra a tabela 1.

TABELA 1

\section{Bases de dados de informação para negócios}

\begin{tabular}{lccc}
\hline & $\begin{array}{c}\text { Dados } \\
\text { confirmados }\end{array}$ & $\begin{array}{c}\text { Dados não } \\
\text { confirmados }\end{array}$ & T otal \\
\hline N úmero de bases de dados & 60 & 74 & $\mathbf{1 3 4}$ \\
Percentagem & 45 & 55 & $\mathbf{1 0 0}$ \\
\hline
\end{tabular}

Fonte: elaborada pela autora. 


\section{Beatriz Valadares C endón}

Pelas limitações da metodologia adotada, não se pode afirmar que a relação de bases de dados obtida seja exaustiva e sua descrição completa. A lista refleteas bases de dados cujos produtores tenham sido citados na literatura de biblioteconomia e ciência da informação ou que tenham sido mencionadas em sites na Internet. Além disso, no desenrolar da pesquisa, constatou-se que novas bases de dados aparecem com freqüência: sites de produtores revisitados após alguns poucos meses já continham outras bases não incluídas inicialmente.

D eve-se ressaltar que, apesar de apenas $45 \%$ dos produtores terem respondido aos e-mails para confirmação e complementação dos dados, como mostra a tabela 1, espera-seque estes estejam corretos, pois foram coletados diretamente nossites dos produtores. Assim, considerou-seque, dianteda atual carência deinformações sobre este tópico, este esforço representava uma contribuição para a área eque seria válido disponibilizar todas as informações coletadas durante o projeto, as quais poderiam servir de ponto de partida para outras iniciativas. Além disso, com os dados obtidos pode-se ter uma idéia inicial de algumas características gerais do conjunto das bases de dados brasileiras de informação para negócios, que serão apresentadas a seguir.

\section{Bases de dados por categoria de informação para negócios}

Foram coletadas informações sobre nove categorias de bases de dados queincluem bases de dados de informações bibliográficas, sobre empresas e produtos, financeiras, estatística eindicadores econômicos, sobre oportunidades de negócios, biográficas, de vocabulário e sobre investimentos. Como mostram as tabelas 2 e 3 , as bases não se encontram uniformemente distribuídas entre as categorias deinformação consideradas. A maioria das bases de dados está na área jurídica (64\%), e todas as demais áreas estão sub-representadas ecarentes debases de dados.

A seguir, apresenta-se descrição do conteúdo de cada categoria. M ais informações, como endereço eU RL dos produtores, estão disponibilizadas no site Fontes Eletrônicas de Informação para N egócios (http:// www.eci.ufmg.br/ cendon).

Informações bibliográficas - As bases de dados bibliográficas são bases de dados referenciais contendo literatura sobre temas tais como empreendedorismo, literatura sobre pequenos negócios, educação e qualificação profissional, economia, administração de empresas, contabilidade, comércio exterior, qualidade,
TABELA 2

Bases de dados por categoria de informação (exceto jurídicas)

\begin{tabular}{lccr}
\hline $\begin{array}{l}\text { Categoria de } \\
\text { informação }\end{array}$ & $\begin{array}{c}\text { Dados } \\
\text { confirmados }\end{array}$ & $\begin{array}{c}\text { Dados não } \\
\text { confirmados }\end{array}$ & Total \\
\hline $\begin{array}{l}\text { Bibliográficas } \\
\text { Empresase }\end{array}$ & 2 & 6 & 8 \\
$\begin{array}{l}\text { produtos } \\
\text { Financeiras }\end{array}$ & 3 & 10 & 13 \\
Estatística e & 0 & 4 & 4 \\
indicadores & 9 & 4 & 13 \\
econômicos & & & \\
Oportunidade de & 1 & 3 & 4 \\
negócios & & 1 & \\
Biográfica & 0 & 1 & 1 \\
Vocabulário & 0 & 4 & 4 \\
Investimento & 0 & $\mathbf{3 3}$ & $\mathbf{4 8}$ \\
Total & $\mathbf{1 5}$ & $\mathbf{6 9}$ & $\mathbf{1 0 0}$ \\
Total (\%) & $\mathbf{3 1}$ & & \\
\hline
\end{tabular}

Fonte: elaborada pela autora.

\section{TABELA 3}

\section{Bases de dados jurídicas por categoria de} informação

\begin{tabular}{lccr}
\hline $\begin{array}{l}\text { Categoria de } \\
\text { informação }\end{array}$ & $\begin{array}{c}\text { Dados } \\
\text { confirmados }\end{array}$ & $\begin{array}{c}\text { Dados não } \\
\text { confirmados }\end{array}$ & Total \\
\hline Doutrina & 3 & 6 & 9 \\
Legislação & 27 & 17 & 44 \\
Jurisprudência & 13 & 13 & 26 \\
Tramitação & 2 & 2 & 4 \\
Vocabulário & 0 & 3 & 3 \\
Total & $\mathbf{4 5}$ & $\mathbf{4 1}$ & $\mathbf{8 6}$ \\
Total (\%) & $\mathbf{5 2 \%}$ & $\mathbf{4 8 \%}$ & $\mathbf{1 0 0 \%}$ \\
\hline
\end{tabular}

Fonte: elaborada pela autora.

micro e pequenas empresas. Registraram-se oito bases bibliográficas, sendo que quatro delas são produzidas pelo Serviço Brasileiro de Apoio às M icro e Pequenas Empresas (Sebrae), como mostra a tabela 4, a seguir.

Informações sobre empresas e produtos - N esta categoria foram identificadas 13 bases de dados que incluem diretórios de escopo etamanhos variados com informações sobre empresas brasileiras, fornecedores, produtos, entidades de apoio a micro e pequenas empresas, assim como associações de classe (tabela 5, a seguir). Os dados incluem nomee descrição da empresa, endereço, lista e descrição de produtos e serviços, entre outros. A D atamaq, produzida pela Abimaq, contém informações sobre máquinas e equipamentos, tais como fabricante (informação cadastral), linha de produção por fabricante, assim como características técnicas por máquina e equipamentos. 


\section{Bases de dados de informação para negócios no Brasil}

TABELA 4

\section{Bases de dados bibliográficas}

\begin{tabular}{ll}
\hline \multicolumn{1}{c}{ Nome } & Descriçâo \\
\hline Base Bibliográfica & Contém quase 41 mil referências bibliográficas de livros, \\
Empresarial (BBE) & revistas, perfis de oportunidades de negócios, catălogos, normas \\
& técnicas, folhetos, fitas de videos, CD.ROMs, sofruare e outros \\
& com ènfase na literatura sobre pequenos negúcios, economia, \\
& markering administração, gestāo e vendas. Não é \\
& comercializada, sendo utilizada apenas para consulta local.
\end{tabular}

$\begin{array}{lll}\text { Biblioteca do } & \text { Contém referências e texto completo em PDF de um acervo } & \text { Sebrae /PB } \\ \text { Emprendedor } & \text { especializado sobre o tema empreendedorismo, formado por } & \text { http://www.bte.com.br/ } \\ & \text { livros, artigos, leis, sofruare e perfis de oportunidades de } & \\ & \text { negócios. E disponibilizada grátis via Interner. }\end{array}$

Biblioteca Virtual

$$
\begin{aligned}
& \text { Contèm aproximadamente } 38 \text { mil registros relativos a todos os } \\
& \text { documentos pertencentes ao acervo do Sebrae nacional. São } \\
& \text { fitas de video, livros e artigos de periòdicos que abordam } \\
& \text { assuntos relacionados à atividade empresarial, tais como } \\
& \text { administraçõo de empresas, contabilidade, comércio exterior, } \\
& \text { qualidade, diveros perfis de oportunidades de negócios } \\
& \text { editados pelo Sebrae, além de documentos relacionados à } \\
& \text { hiśória das micro e pequenas empresas no Brasil. } \\
& \text { É pesquisável gratuitamente via Internet. }
\end{aligned}
$$

Produtot
Sebrae/MG
http://www.sebraenet.com.br/

Sebrae

http://www sebrae.com.br/

\author{
Ediçio Sebrae
}

Orientador / Adviser

- Indice Brasileiro de

Bibliografia

Econômica (IBBE)

\section{Orientador / Adviset \\ - Indice Brasileiro de}

Bibliografia de

Administraçāo (IBBA)

\section{Contém referéncias bibliográficas e resumo para obras referenciais para o segmento empresarial nos seus mais variados campos de atuaçāo. Esta disponivel via Intemet.}

Sebrae

http://www sebrae com.br/

Contèm literatura publicada em revistas especializadas, livros, dissertaçôes e teses e legislação. Ė organizada pelo professor

\begin{tabular}{|c|c|c|}
\hline Perie & $\begin{array}{l}\text { Contèn cerca de } 9 \text { mil referẽncias bibliogrảficas de artigos de } \\
\text { periódicos nacionais de economia, monografias de graduação, } \\
\text { relatórios de pesquisa, videos, publicaçōes seriadas e follhetos de } \\
\text { Economia, documentos. Pode ser acesada gratuitamente via } \\
\text { Internet. }\end{array}$ & $\begin{array}{l}\text { Unicamp } \\
\text { http://www:unicamp.br/bc/bases.htm }\end{array}$ \\
\hline $\begin{array}{l}\text { Referẻncias } \\
\text { Bibliograficas sobre } \\
\text { Educação e } \\
\text { Qualificação } \\
\text { Profissional (EQP) }\end{array}$ & $\begin{array}{l}\text { Contém documentos sobre qualificaça profissional, } \\
\text { produzidos a partir de } 1980 \text {. Disponivel via CD-ROM e } \\
\text { Internet. }\end{array}$ & $\begin{array}{l}\text { Fundação Carlos Chagas } \\
\text { http://www:foc.org.br/pesquisa/biblio } \\
\text { teca/equ html }\end{array}$ \\
\hline
\end{tabular}
Dercio Garcia Munhoz. Fornecida via Internet ou CD-ROM.

Contém literatura publicada em revistas especializadas, livros, dissertaçôes e teses e legislaçāo. É organizada pelo professor Dércio Garcia Munho:. Fornecida via Internet ou CD-ROM.
Brasilia Computadores e Sistemas (BCS) http://www.cd-graf.combr/orientador/

Brasilia Computadores e Sistemas (BCS) http://www.cd-graf.com.br/orientador/

Fonte: elaborada pela autora. 
Beatriz Valadares C endón

TABELA 5

Informações sobre empresas e produtos

\begin{tabular}{|c|c|c|c|c|}
\hline Nome & Descriçlo & Produtor & $\begin{array}{l}\text { N. de } \\
\text { Registros }\end{array}$ & Escopo \\
\hline $\begin{array}{l}\text { Datamaq - } \\
\text { Banco de } \\
\text { Dados em } \\
\text { Máquinase } \\
\text { Equipamentos }\end{array}$ & $\begin{array}{l}\text { Contérn informạ̄ōes sobre máquinas e equiparnentos, tais } \\
\text { como fabricante (informaçío cadastral), linha de produçio por } \\
\text { fabricante e caracteristicas técnicas por máquina e } \\
\text { equipamentos. Disponivel na Internet mediante assinatura. }\end{array}$ & $\begin{array}{l}\text { Abimaq / Sindmaq } \\
\text { http://www.abimaq.org.br/ }\end{array}$ & $\begin{array}{l}320.000 \\
\text { produtos } \\
3.100 \\
\text { empresas }\end{array}$ & Brasil \\
\hline $\begin{array}{l}\text { Base de Dados } \\
\text { Sebrae/ES }\end{array}$ & $\begin{array}{l}\text { Conjunto de bases de dados que contempla informaçốes } \\
\text { cadastrais de empresas do Espirito Santo. A base Fornecedores } \\
\text { contém mais de } 8 \text { rail empresas cadastradas. Franquias no Brasil } \\
\text { contém } 900 \text { registros, e Entidades de Apojo à Pequena e Médiar } \\
\text { Empress, } 600 \text { registros. Disponibilizada grátis na Internet. }\end{array}$ & $\begin{array}{l}\text { Sebrae/ES } \\
\text { http://www.sebraces.com.br/ }\end{array}$ & 8.900 & Espirito Santo \\
\hline $\begin{array}{l}\text { Cadastro de } \\
\text { Empresas }\end{array}$ & $\begin{array}{l}\text { Diretório com dados sobre mais de } 12 \text { mil empresas do Estado } \\
\text { do Rio de Janeiro. Disponivel localmente. }\end{array}$ & $\begin{array}{l}\text { Sebrae/RJ } \\
\text { http: } / / \text { www.sebraerj.com.br// }\end{array}$ & 12.000 & Rio de Janeiro \\
\hline Database Oesp & $\begin{array}{l}\text { Diretótio de empresas em todos os estados brasileiros, com } \\
\text { nome, endereço, telefone e outras informaçóes. Pode ser } \\
\text { segmentado por setor, produtos, faixa de CEP e porte da } \\
\text { empresa. Disponivel gratuitamente na Internet. }\end{array}$ & $\begin{array}{l}\text { OESP Midia S/A } \\
\text { http: } / / \text { www.listasamarelas.com. } \\
\text { br/ }\end{array}$ & 2 milhōes & Brasil \\
\hline Mercacard & $\begin{array}{l}\text { Base de dados de empresas com potencial de internacionalizaçáo } \\
\text { de suas operaços. Disponivel via consultoria especifica. }\end{array}$ & $\begin{array}{l}\text { Mercocard } \\
\text { http: } / / \text { www.meroocard.com.br/ }\end{array}$ & & Brasil \\
\hline $\begin{array}{l}\text { Banco de } \\
\text { negócios e } \\
\text { oportunidades }\end{array}$ & $\begin{array}{l}\text { Diretório de empresas associadas à Fiesp/Ciesp. Registra quase } \\
7 \text { mil e } 500 \text { empresas em } 447 \text { ramos de atividades. Fornece para } \\
\text { cada empresa razaáo social, enderęo, ramo, produtos e serviģos } \\
\text { dassificados de acordo com a Nomenclatura Comum do } \\
\text { Mercosul. Dudos sío de responsabilidade das empresas } \\
\text { cadastradas. Disponivel gratuitamente via Internet. }\end{array}$ & $\begin{array}{l}\text { Federação e Centro das } \\
\text { Indústrias do Estado de São } \\
\text { Paulo (Fiesp/Ciesp) } \\
\text { http://www2.ciesp.org.br/opor- } \\
\text { tunidades/bno.htm }\end{array}$ & 7.388 & São Paulo \\
\hline $\begin{array}{l}\text { Fiesp/Ciesp - } \\
\text { Cadastro das } \\
\text { Associaçóes de } \\
\text { Classe }\end{array}$ & $\begin{array}{l}\text { Cadastro de Associações de Classe da Fiesp/Ciesp. Contém } \\
\text { endereço e nome dos executivos responsíveis. Disponivel via } \\
\text { consultoria específica. }\end{array}$ & $\begin{array}{l}\text { Federaçio e Centro das } \\
\text { Indüstrias do Estado de São } \\
\text { Paulo (Fiesp//Ciesp) } \\
\text { http } / / \text { www.fiesp.org.br/negoci } \\
\text { os/cadindl.htm }\end{array}$ & - & Sào Paulo \\
\hline $\begin{array}{l}\text { Fiesp/Ciesp - } \\
\text { Cadastro } \\
\text { Industrial }\end{array}$ & $\begin{array}{l}\text { Registra } 15 \text { mil empresas cadastradas na Fiesp/Ciesp. Contém } \\
\text { razäo social, nome do principal exocutivo, endereç, ramo, } \\
\text { número de empregados, tamanho. Visa a identificar } \\
\text { fornecedores e clientes para a indústria. Disponivel via } \\
\text { consultoria especifica. }\end{array}$ & $\begin{array}{l}\text { Federaçấo e Centro das } \\
\text { Indústrias do Estado de Sāo } \\
\text { Paulo (Fiesp/Ciesp) } \\
\text { http: } / / \text { www.fiesp.org.br/negoci } \\
\text { os/cadindl.htm }\end{array}$ & 15.000 & $\begin{array}{l}\text { Empresas } \\
\text { associadas à } \\
\text { Fiesp }\end{array}$ \\
\hline $\begin{array}{l}\text { Cadastro } \\
\text { Empresarial }\end{array}$ & $\begin{array}{l}\text { Consiste de duas bases de dados: o cadastro Eletrônico de } \\
\text { Enderegos de Entidades Empresartiais com informaçũes } \\
\text { cadastrais das empresas e sobre seus empresărios, executivos e } \\
\text { ó́cnicos. O Cadastro Sindical da Indüstria contém nome, } \\
\text { endereço e nomes de presidentes e principais executivos. } \\
\text { Disponivel gratuitamente na Internet. }\end{array}$ & $\begin{array}{l}\text { Confederaçáo Nacional da } \\
\text { Indústria (CNI) }\end{array}$ & & $\begin{array}{l}\text { Empresas } \\
\text { associadas ao } \\
\text { CNI }\end{array}$ \\
\hline $\begin{array}{l}\text { BVRJ - } \\
\text { Sociedades } \\
\text { Membros }\end{array}$ & $\begin{array}{l}\text { Contém informaçóes sobre as sociedades membros da Bolsa de } \\
\text { Valores do Rio de Janeiro (banoos, corretoras e distribuidoras). } \\
\text { Disponivel gratuitamente na Internet. }\end{array}$ & $\begin{array}{l}\text { Bolsa de Valores do Rio de } \\
\text { Janeiro (BVRJ) } \\
\text { http://www.bvrj.com.br/Cor- } \\
\text { retoras/Soccor.htm }\end{array}$ & & $\begin{array}{l}\text { Sociedades } \\
\text { membros da } \\
\text { BVRJ }\end{array}$ \\
\hline $\begin{array}{l}\text { Business } \\
\text { Connection }\end{array}$ & $\begin{array}{l}\text { Diretório das empresas e individuos associados à Cảmara } \\
\text { Americana de Comércio. Contém nome, endereço, principais } \\
\text { executivos, númeto de funcionários, produtos e serviças e seu } \\
\text { código SIC (Standard Industrial Classification). Disponivel } \\
\text { granuitamente na Internet. }\end{array}$ & $\begin{array}{l}\text { Càmara Americana de } \\
\text { Comércio (AMCHAM) } \\
\text { http: //www.amcham.com.br/ }\end{array}$ & 1900 & $\begin{array}{l}\text { Empresas } \\
\text { associadas à } \\
\text { Câmata } \\
\text { Americana de } \\
\text { Comércio }\end{array}$ \\
\hline $\begin{array}{l}\text { Duns } 10000- \\
\text { DDM }\end{array}$ & $\begin{array}{l}\text { DUNS 10000-DDM, produzida pela Duns \& Bradstreet do } \\
\text { Brasil, contém informaçes sobre cerca de } 9 \text { mil empresas e é } \\
\text { atualizada diariamente; Disponivel em CDROM, disquete e via } \\
\text { consultoria especifica. }\end{array}$ & $\begin{array}{l}\text { Dun \& Brastreet do Brasil Ltda. } \\
\text { http } / / \text { www.amcham.com.br/ }\end{array}$ & 8.600 & Brasil \\
\hline $\begin{array}{l}\text { Biz2Biz } \\
\text { Directory }\end{array}$ & $\begin{array}{l}\text { Biz2Biz Directory, do Grupo Quattro Digital Media, é um } \\
\text { catálogo com cerca de } 3 \text { mil fornecodores business to business } \\
\text { brasileitos, ou seja, um catalogo de empresas que fazem negócics } \\
\text { com oustras empresa. Os dados incluem nome e descriçăio da } \\
\text { empresa, endereço, lista e descriçâo de produtos e serviços, entre } \\
\text { outros. Ê disponivel gratuitamente na Internet. }\end{array}$ & $\begin{array}{l}\text { Grupo Quattro Digital Media } \\
\text { http: } / / \text { www.quattro,com.br/ }\end{array}$ & 3.000 & $\begin{array}{l}\text { Empresas } \\
\text { Biz2Biz }\end{array}$ \\
\hline
\end{tabular}

Fonte: elaborada pela autora. 
TABELA 6

\section{Bases de dados financeiras}

\begin{tabular}{|c|c|c|}
\hline Nome & Descriçāo & Produtor \\
\hline $\begin{array}{l}\text { Bovespa - } \\
\text { Companhias Listadas }\end{array}$ & $\begin{array}{l}\text { Contém informaçōes sobre as companhias participantes da Bolsa de } \\
\text { Valores de São Paulo. Fornece dados cadastrais como identificạ̧ōes, } \\
\text { endereço, contatos, data de publicaçōes de documentos como aviso aos } \\
\text { acionistas e demonstraçôes financeiras, tipo de controle acionário, } \\
\text { características da empresa, titulos de jornais onde a empresa divulga } \\
\text { informações, bolsas de valores onde a empresa possui registros, situação } \\
\text { financeira (operacional ou concordatária), capital subscrito e alteraçeses, } \\
\text { demonstrativo de evolução do capital social etc. Disponivel } \\
\text { gratuitamente via Internet. }\end{array}$ & $\begin{array}{l}\text { Bolsa de Valores do Estado de São } \\
\text { Paulo (Bovespa) } \\
\text { http://www.bovespa.com.br/ }\end{array}$ \\
\hline $\begin{array}{l}\text { Mil Maiores Empresas } \\
\text { da América Latina }\end{array}$ & $\begin{array}{l}\text { Base de dados, de acesso grátis, disponivel no portal Investnews.net. } \\
\text { alimentado com as principais informaçōes sobre as mil maiores empresas } \\
\text { da América Latina. Contém informaçōes básicas sobre uma empresa } \\
\text { como receita bruta, receita líquida, lucro bruto, lucro operacional, lucro } \\
\text { liquido, ativo fixo, ativo total, passivo total, património liquido e capital } \\
\text { social. Disponivel gratuitamente na Internet. }\end{array}$ & $\begin{array}{l}\text { Gazeta Mercantil } \\
\text { http://www. } 1000 \text { maiores.com.br/ }\end{array}$ \\
\hline $\begin{array}{l}\text { Banco de Dados da } \\
\text { Serasa }\end{array}$ & $\begin{array}{l}\text { Banco de dados sobre pessoas, empresas e grupos econômicos contendo } \\
\text { análises e informações sobre débitos em atraso, abrangendo protestos, } \\
\text { cheques sem fundos, falências, concordatas, açōes judiciais. É o maior da } \\
\text { América Latina, dispondo do registro de todas as empresas legalmente } \\
\text { constituidas no Brasil, cerca de } 9 \text { milhōes, e sobre todos os consumidores } \\
\text { do Brasil com alguma atividade económica. Fornece subsidios à maioria } \\
\text { das decisões de crédito tomadas no Brasil. Disponivel via consultoria } \\
\text { especifica. }\end{array}$ & $\begin{array}{l}\text { Serasa } \\
\text { http } / / \text { www.serasa.com.br/ }\end{array}$ \\
\hline Sabe & $\begin{array}{l}\text { Sistema de análise de balanços empresariais. Um instrumento de apoio } \\
\text { às decisð̋es de investimento em aç̋̄es. Contém dados de } 450 \text { companhias } \\
\text { de capital aberto listadas nas bolsa de valores do pais. Disponibiliza os } \\
\text { seguintes recursos: informaçōes trimestrais e anuais sobre as } \\
\text { demonstraçōes financeiras (balanço patrimonial, demonstrativo de } \\
\text { resultados e demonstrativo de origens e aplicaçóes de recursos), } \\
\text { apresentação dos valores das contas em real, dólar e moeda da época } \\
\text { corrigida para o valor presente, } 50 \text { indicadores económico-financeiros } \\
\text { (liquidez, estrutura de capital, rentabilidade e outros). Disponibilizada na } \\
\text { Internet. }\end{array}$ & $\begin{array}{l}\text { Instituto Brasileiro de Mercado de } \\
\text { Capitais (IBMEC) } \\
\text { http://www.sabe.com.br/fr_oque. } \\
\text { htm }\end{array}$ \\
\hline
\end{tabular}

Fonte: elaborada pela autora.

Informações financeiras sobre empresas - Foram identificadas quatro bases de dados com informações financeiras sobreempresas (tabela 6). Essas bases contêm dados cadastrais das empresas e podem conter informações básicas sobre uma empresa como receita bruta, receita líquida, lucro operacional, ativo, passivo, patrimônio, capital, débitos em atraso e outras informações para decisões de crédito, sobre controle acionário, relatórios submetidos à CVM , demonstrações financeiras (Balanço Patrimonial, D emonstrativo de Resultados e D emonstrativo de O rigens e Aplicações de Recursos), entreoutros.

Informações estatísticas e indicadores Comparado com outros, este setor está relativamente bem representado, com 13 bases de dados (tabela 7, a seguir). São bases do tipo numérico ou estatístico, contendo indicadores econômicos, sociais, financeiros, políticos e administrativos em áreas como emprego, comércio exterior, preços, contabilidade social, serviços, finanças públicas, população, salário e renda, produção, consumo e vendas, contas nacionais, moeda ecrédito, juros, câmbio ebalanço depagamentos. Podem ser usadas para atividades de planejamento e pesquisa, estudo de mercado ou para o conhecimento da realidade brasileira. São produzidas por órgãos do governo federal ou estadual, bancos, institutos de pesquisa, empresas privadas e pela Confederação N acional da I ndústria (CN I). Por serem, em sua maioria, produzidas por instituições sem fins lucrativos, são quase todas disponibilizadas gratuitamente via Internet. Exceções são as bases produzidas pelo setor privado, como as do CNI (Comex e Indicadores econômicos) edo Target (Brasil em foco). 


\section{Beatriz Valadares C endón}

\section{TABELA 7}

\section{Informação estatística e indicadores}

\begin{tabular}{|c|c|c|}
\hline Nome & Descrição & Produtor \\
\hline Bases de dados do IBGE & $\begin{array}{l}\text { Divulga os resultados das pesquisa feitas pelo IBGE relativas a } \\
\text { estatisticas de âmbito social c demográfico, estatisticas da } \\
\text { agropecuária, estatisticas econômicas e índices de preços. Disponivel } \\
\text { gratuitamente na Internet. }\end{array}$ & $\begin{array}{l}\text { Instituto Brasileiro de Geografia e } \\
\text { Estatistica (IBGE) } \\
\text { http://www.ibge.gov.br/ }\end{array}$ \\
\hline FGVDados & $\begin{array}{l}\text { Banco de dados de indicadores econômicos (indices de preços, preços } \\
\text { recebidos e pagos pelos produtores agricolas, sondagens industriais } \\
\text { etc.) do Instituto Brasileiro de Economia da FGV. Contém mais de } \\
2.500 \text { séries de valores obtidos através do Instituto Brasileiro de } \\
\text { Economia (IBRE) ou de outras instituiçōes de grande credibilidade. } \\
\text { Versão limitada disponivel gratuitamente via Internet (ou completa } \\
\text { mediante assinatura). }\end{array}$ & $\begin{array}{l}\text { Fundaçāo Getulio Vargas (FGV) } \\
\text { http://fgvdados.fgv.br/ }\end{array}$ \\
\hline $\begin{array}{l}\text { BDEPE - Base de Dados } \\
\text { do Estado (Pernambuco) }\end{array}$ & $\begin{array}{l}\text { Banco de dados socioeconỏmicos do Estado de Pernambuco, } \\
\text { abrangendo demografia, emprego e renda, educação, saúde, habitação } \\
\text { e saneamento, agropecuária, indústria, comércio, serviços, contas } \\
\text { regionais, transporte, finanças públicas e outras. Disponivel }\end{array}$ & $\begin{array}{l}\text { Instituto de Planejamento de } \\
\text { Pernambuco (Condepe) } \\
\text { http } / / \text { www.condepe.pe.gov.br/bde } \\
\text { htm }\end{array}$ \\
\hline
\end{tabular}

$\begin{array}{ll}\text { Base Anpei } & \begin{array}{l}\text { Contém indicadores empresariais de inovação tecnológica que } \\ \text { possibilitam detectar tendências em inovação tecnológica entre } \\ \text { empresas nacionais e estrangeiras. Versão limitada disponivel } \\ \text { gratuitamente na Internet. }\end{array} \\ \text { BDE - Base de Dados do } & \begin{array}{l}\text { Contempla } 26 \text { milhōes de itens de dados e referẽncias das áreas } \\ \text { económica, politica, administrativa, fisica e social do Paraná. Grátis } \\ \text { na Internet mediante autorização. }\end{array}\end{array}$

$\begin{array}{ll}\text { Brasil em Foco } & \text { Banco de dados secundários, baseados em dados divulgados pelo } \\ & \text { IBGE e outras instituiçoes oficiais. Possui informaçós sobre a } \\ \text { quantidade de empresas em cada município brasileiro, segmentadas } & \text { segundo sua principal atividade. Dispontvel em CD-ROM. } \\ \text { Caged - Cadastro Geral } & \text { Movimento de admitidos e desligados do Caged. A origem dos dados } \\ \text { de Empregados e } & \text { săo os estabelecimentos empregadores. Em CD-ROM. }\end{array}$

Desempregados

RAIS - Relaçăo Anual de Levanta toda a informaçăo relativa ao mercado de trabalho formal Informaçŏes Sociais brasileiro. Contém informaçōes sobre o estoque e remuneraçăo de emprego e sobre estabelecimentos declarantes. Em CD-ROM.

Comex - Estatistica de Base de dados com informạ̧óes estatísticas sobre as exportaçōes e

Comércio Exterior importaçós brasileiras em nivel de produto, pais, empresa e estado. Possui mais de 140 mil registros e é disponibilizada via consultoria especifica.

Banco de Dados do Nordeste Focalizada no Nordeste, contém informaçōes de caráter econồmico e demográfico em niveis municipal e estadual (indicadores econômicos, sociais, financeiros, politicos). Disponivel localmente.

Indicadores Econômicos Fornece informaçōes sobre a economia brasileira. Os dados sāo apresentados $\mathrm{em}$ cinco blocos: atividade econômica, política monetária e fiscal, setor externo e dados estruturais. Disponivel mediante assinatura.

Anuário Estatistico de Contém informaçōes sobre os diferentes setores de atividade Estado do Rio de Janeiro econômica e dados sobre aspectos fisico-territoriais, sociodemográficos, de infra-estrutura, econômicos e de fínanças do Estado do Rio de Janeiro. Versāo limitada disponivel via Internet ou Associação Nacional de Pesquisa, Desenvolvimento \& Engenharia das Empresas Inovadoras (Anpei) http://www.anpei.org.br/ Centro Estadual de Estatistica (CEE) do Instituto Paranaense de Desenvolvimento Econômico $\mathrm{e}$ Social (Ipardes) http://www.ipardes.gov.br/ Target - Pesquisas e Serviços de Marketing Ltda.

http://www,targetmark.com.br/

Ministério do Trabalho e Emprego http://www.mte.gov.bt/

Ministério do Trabalho e Emprego http://www,mte.gov.br/

Confederaçio Nacional da

Indústria (CNI)

http://www.cni.org.br

Banco do Nordeste

http://www.banconordeste.gov.br/

Confederaçāo Nacional da

Indùstria (CNI)

http: //www.cni.org.br

Fundaçāo Centro de Informaçōes e Dados do Rio de Janeiro (CIDE) http: //www.cide.rj-gov.br/ completa em CD-ROM.

Base Ipeadata Dados macroeconòmicos sobre o Brasil. Contém mais de 5 mil séries - sendo 3 mil de uso público com acesso gratuito via Internet. Cobre populaçāo, emprego, salário e renda, produçâo, consumo e vendas, contas nacionais, finanças públicas, moeda e crédito, preços, juros, cåmbio, balanço de pagamentos, comércio exterior c cconomia internacional. Grátis na Internet.

Fonte: elaborada pela autora. 
TABELA 8

\section{Bases de dados de oportunidades de negócios}

\begin{tabular}{|c|c|c|}
\hline Nome & Descrição & Produtor \\
\hline Bolsa de Negócios & $\begin{array}{l}\text { É um serviço de promoção de negócios que visa a identificar } \\
\text { e aproximar compradores e fornecedores de produtos, } \\
\text { serviços e oportunidades de negócios. É feito por } \\
\text { cadastramento de informaçōes em uma grande base de } \\
\text { dados. Os dados disponiveis encontram-se segmentados da } \\
\text { seguinte forma: Cadastro de empresas - onde empresas de } \\
\text { todo o pais cadastram seus produtos, serviços e/ou residuos; } \\
\text { Oportunidades - onde são cadastradas oportunidades de } \\
\text { negócios nacionais e internacionais. Atualmente sāo cerca de } \\
48 \text { mil empresas cadastradas, } 135 \text { mil produtos e } 7 \text { mil } \\
\text { oportunidades de negócios. Disponivel gratuitamente via } \\
\text { Internet. }\end{array}$ & $\begin{array}{l}\text { Sebrae } \\
\text { http://www.sebrae.com.bt/ }\end{array}$ \\
\hline $\begin{array}{l}\text { Bolsa de Negócios } \\
\text { Turisticos }\end{array}$ & $\begin{array}{l}\text { Contém dados sobre o investidor (nome, endereço, e-mail etc.) } \\
\text { e sobre investimento (localidade, pretensão, produto e } \\
\text { área de investimento). Fornece informaçōes necessárias para } \\
\text { os empresários no desenvolvimento de seus projetos, } \\
\text { cadastro das empresas prestadoras de serviço e fornecedores } \\
\text { de produtos entre outras. É produzida pela Embratur } \\
\text { (Instituto Brasileiro de Turismo) e disponibilizada } \\
\text { gratuitamente via Internet. }\end{array}$ & $\begin{array}{l}\text { Instituto Brasileiro de Turismo } \\
\text { (Embratur) } \\
\text { http://www.embratur.gov.br/ }\end{array}$ \\
\hline Franquia & $\begin{array}{l}\text { Visa a divulgar as franquias em expansăo no Brasil, } \\
\text { disponibilizando informaçōes sobre taxas, praças de } \\
\text { interesse, capital de implantação, prazo de retorno do } \\
\text { investimento etc. Produzida pelo Sebrae/CDI (Centro de } \\
\text { Documentação e Informação), contém cerca de } 1.000 \\
\text { registros. Disponivel gratuitamente via Internet. }\end{array}$ & $\begin{array}{l}\text { Sebrae/CDI (Centro de } \\
\text { Documentação e Informação) } \\
\text { http://www.sebrae.com.br/ }\end{array}$ \\
\hline Ponto de Partida & $\begin{array}{l}\text { Fornece subsidios para a elaboraçāo do produto "Ponto de } \\
\text { Partida" do serviço de Resposta Técnica do Sebrae. Por meio } \\
\text { deste produto, o Sebrae fornece orientaçōes sobre abertura } \\
\text { de um negócio, como identificar consumidores, } \\
\text { concorrentes, legislação pertinente, fornecedores de } \\
\text { maquinários e equipamentos etc. Esta base de dados não é } \\
\text { disponibilizada para o público, apenas o produto Ponto de } \\
\text { Partida. Possui mais de } 700 \text { registros sobre oportunidades de } \\
\text { negócios. }\end{array}$ & $\begin{array}{l}\text { Sebrae/MG } \\
\text { http://www.sebraenet.com.br/ }\end{array}$ \\
\hline
\end{tabular}

Fonte: elaborada pela autora.

O portunidades de negócios - N esta categoria foram incluídas bases de dados que visam a auxiliar os empreendedores a identificar e desenvolver oportunidades de negócios. Quatro bases foram identificadas, sendo três delas do tipo diretório e uma em texto completo ( tabela 8). Dentre os produtores, destaca-se o Sebrae, responsável por três bases, as quais subsidiam seus produtos e serviços. As bases Bolsa de $\mathrm{N}$ egócios, Bolsa de $\mathrm{N}$ egócios Turísticos, e Franquias dependem dos próprios interessados para inclusão dos dados e estão disponibilizadas via Internet para consulta grátis. A Ponto de Partida é consultada apenas internamente para consultorias específica.
Biográficas - Apenas uma base foi encontrada nesta categoria que contempla informações sobre perfis biográficos de personalidades ligadas ao mundo empresarial. Personalidades em D estaque (http:// www.investnews.net/) é produzida pelaG azeta M ercantil e disponibiliza, gratuitamente na Internet, informações mais recentes veiculadas pela Gazeta a respeito de personalidades em destaque.

Vocabulário - A base de dados Tesauro (http:// www.cni.org.br/f-ps-tesauro.htm), produzida pela Confederação N acional da Indústria ( $C N I$ ), contém vocabulário controlado nas seguintes áreas: economia, direito, tecnologia industrial, infra- 
TABELA 9

\section{Bases de dados de informação para investimento}

\begin{tabular}{|c|c|c|}
\hline Nome & Descriçāo & Produtor \\
\hline $\begin{array}{l}\text { Brazilian } \\
\text { Competitive Sites }\end{array}$ & $\begin{array}{l}\text { Banco de dados on-line de informações } \\
\text { sociodemográficas e econômico-negociais sobre os } 500 \\
\text { maiores municipios brasileiros. Grátis na Internet. }\end{array}$ & $\begin{array}{l}\text { Câmara Americana de Comércio } \\
\text { http://www.amcham.com.br/ }\end{array}$ \\
\hline $\begin{array}{l}\text { BIL - Brazil } \\
\text { Investment Link }\end{array}$ & $\begin{array}{l}\text { Conjunto de bases de dados sobre os rumos da } \\
\text { internacionalização da economia brasileira, avaliação das } \\
\text { tendências do investimento de empresas nacionais e } \\
\text { estrangeiras, tendências globais de investimento, } \\
\text { mudanças na regulamentaçāo, propriedade intelectual e } \\
\text { análises setoriais. Parte integrante do sistema de } \\
\text { informação da Câmara Americana de Comércio de São } \\
\text { Paulo. Grátis na Internet. }\end{array}$ & $\begin{array}{l}\text { Câmara Americana de Comércio } \\
\text { http://www.amcham.com.br/ }\end{array}$ \\
\hline Investnews & $\begin{array}{l}\text { Sistema de notícias e cotaçóes em tempo real da Gazeta } \\
\text { Mercantil, maior jornal de economia e negócios do } \\
\text { Brasil. Contém serviços pagos para assinantes e serviços } \\
\text { gratuitos com acesso limitado às informaçōes. Contèm } \\
\text { Banco de Noticias, Gazeta Latino-Americana, Jornais } \\
\text { Regionais, Jornalismo Setorial, Fundos, Balanços Anuais } \\
\text { de Empresas. Oferece acesso limitado gratuitamente via } \\
\text { Internet. O acesso completo é mediante assinatura. }\end{array}$ & $\begin{array}{l}\text { Gazeta Mercantil } \\
\text { http://www.investnews.net/ }\end{array}$ \\
\hline $\begin{array}{l}\text { CMA - Consultoria, } \\
\text { Métodos, Acessoria e } \\
\text { Mercantil Ltda. }\end{array}$ & $\begin{array}{l}\text { Serviço de informação sobre mercados financeiro e } \\
\text { agricola. Faz cobertura completa dos mercados de } \\
\text { açôes, renda fixa, câmbio e de commodities, com } \\
\text { noticias advindas da Agência Brasil, Valor Econômico, } \\
\text { Dinheiro Vivo, Folha News, Gazeta Mercantil entre } \\
\text { outras. Contém ainda análises e cotaçōes, em tempo } \\
\text { real. No àmbito internacional monitora os principais } \\
\text { fatos e acontecimentos que movem os mercados. Via } \\
\text { Internet (gratuitamente para acesso limitado e mediante } \\
\text { assinatura para acesso completo). }\end{array}$ & $\begin{array}{l}\text { CMA - Consultoria, Métodos, } \\
\text { Acessoria e Mercantil Ltda. } \\
\text { hetp://www.cma.com.br/ }\end{array}$ \\
\hline
\end{tabular}

Fonte: elaborada pela autora.

estrutura (energia, transporte, telecomunicações), informática, administração, ação social e meio ambiente. É disponibilizada via CD-ROM .

Informação para investimento - Foram encontradas quatro bases na categoria de informação para investimento (tabela 9). Elas contêm informações socioeconômicas demunicípios brasileiros, avaliação das tendências de investimentos de empresas, sistemas de notícias econômicas e análises e cotações (de ações, moedas e outras) em tempo real. Servem para subsidiar decisões de investimento.

Informação jurídica - A área jurídica responde por 86 das 134 bases encontradas. Essas bases se dividem em doutrina, legislação, jurisprudência, tramitação de matérias e vocabulário (bases de dados de dicionários ou tesauros jurídicos). D evido ao seu grande número e por merecerem análise em separado, não serão aqui listadas. Provavelmente existe uma gama de fatores que poderia explicar a concentração de bases de dados na área jurídica. U m destes fatores poderia ser o fato de a área ser intensiva em informações. Vários dos elementos da cadeia de produtores de informação jurídica são potenciais produtores de bases de dados. Por exemplo, existe considerável número de editoras de literatura jurídica; muitas dessas se tornaram produtoras de bases de dados à medida que decidiram colocar suas obras impressas em formato eletrônico. D eve ter influenciado a área também a liderança do Prodasen e Senado Federal, extremamente atuantes como apoio ao Congresso $\mathrm{N}$ acional e com facilidade de acesso a financiamento para seus projetos. D evido ao Prodasen, a área já era servida por um conjunto de bases de dados muito antes que outros campos. M uitas das bases de dados são também produzidas por outros órgãos do governo, como a extensa rede de tribunais eassembléias legislativas estaduais. 


\section{Bases de dados por tipo}

Abaixo estão definidos os tipos de bases de dados encontrados:

\section{- Vocabulário:}

- Dicionário: a base de dados contém lista de termos, particulares para determinada disciplina ou assunto, com verbetes explicativos.

- Tesauro: a base de dados contém lista hierárquica de termos de vocabulário controlado, que descrevem os assuntos de documentos em determinada área. Contêm também relações entre os termos.

- Referência bibliográfica: a base de dados contém referências bibliográficas de documentos ( por exemplo: artigos de revistas, relatórios, patentes, dissertações, anais de congresso, livros, itens de jornais, material jurídico). Podeincluir resumos.

- Texto completo: a base de dados contém o texto completo de documentos (por exemplo: artigos de revistas, jornais, relatórios, material jurídico etc.). Os documentos são armazenados de forma a permitir a pesquisa em cada palavra do documento.

- Texto completo com imagens digitalizadas: a base de dados contém os documentos originais em texto completo (por exemplo: artigos de revistas, jornais, relatórios, material jurídico etc.). O s documentos são armazenados em forma de imagens e não permitem a pesquisa por palavra.

- Estatística e indicadores econômicos: a base de dados contém uma coleção de dados quantitativos e numérico-estatísticos. Representações de manipulações estatísticas dos dados mostrando medidas ao longo do tempo de determinada variável são incluídas.

- Numérica: a base de dados contém coleção de dados numéricos, incluindo quotações de ações, preços e outros dados numéricos. Propriedades, estatísticas e séries históricas são excluídas.

- Diretório: a base de dados contém lista de endereços para contato de pessoas, organizações, publicações, empresas ou outras entidades.

Estes tipos estão distribuídos entre as bases conforme mostrado na tabela 10.
TABELA 10

Bases de dados por tipo

\begin{tabular}{|c|c|c|c|c|c|c|}
\hline \multirow[b]{2}{*}{ Tipo } & \multicolumn{2}{|c|}{ Juridica } & \multicolumn{2}{|c|}{ Outras áreas } & \multicolumn{2}{|c|}{ Total } \\
\hline & $\begin{array}{c}\text { Quant. } \\
\text { Total }\end{array}$ & $\begin{array}{c}\% \text { (sobre } \\
86)\end{array}$ & $\begin{array}{c}\text { Quant, } \\
\text { Total }\end{array}$ & $\begin{array}{c}\% \text { (sobre } \\
48)\end{array}$ & $\begin{array}{l}\text { Quant. } \\
\text { Total }\end{array}$ & $\begin{array}{c}\% \\
\text { (sobre 134) }\end{array}$ \\
\hline Dicionário & 3 & $3 \%$ & 0 & 0 & 3 & $2 \%$ \\
\hline Tesauro & 1 & $1 \%$ & 1 & 2 & 2 & $1 \%$ \\
\hline $\begin{array}{l}\text { Referéncia } \\
\text { bibliogrifica }\end{array}$ & 16 & $19 \%$ & 11 & 23 & 27 & $19 \%$ \\
\hline $\begin{array}{l}\text { Texto } \\
\text { completo }\end{array}$ & 71 & $83 \%$ & 7 & 15 & 78 & $59 \%$ \\
\hline Estaristica & & $0 \%$ & 2 & 4 & 2 & $1 \%$ \\
\hline Numérica & & $0 \%$ & 15 & 31 & 15 & $11 \%$ \\
\hline Diretório & & $\infty \%$ & 19 & 40 & 19 & $14 \%$ \\
\hline $\begin{array}{l}\text { Não } \\
\text { fornecida }\end{array}$ & 3 & $3 \%$ & 2 & 4 & 5 & $4 \%$ \\
\hline Total & 94 & & 57 & & 151 & \\
\hline
\end{tabular}

Fonte: elaborada pela autora.

O bservação: os dados totalizam mais de $100 \%$ porque as bases podem conter mais de um tipo de informação.

$\mathrm{N}$ a tabela 10, deve ser observado que algumas bases de dados contêm mais de um tipo de dado, razão pela qual os percentuais finais somam mais que $100 \%$. D estaca-se que $78 \%$ das bases de dados jurídicas são em texto completo e 17\% na forma de referência bibliográfica. Já entre os outros tipos de bases de dados, $40 \%$ são diretórios, $31 \%$ são numéricas. As bases de dados numéricas e estatísticas estão localizadas dentro das categorias de Informações financeiras, de Investimento eEstatísticas e indicadores econômicos, como era dese esperar. As do tipo diretório encontram-senas categorias I nformação sobre empresas e produtos e 0 portunidade denegócios.

\section{Bases de dados por freqüência de atualização}

Apesar de muitas instituições não terem respondido ao questionário, informação sobre a freqüência de atualização constava de razoável número desites, efoi possível compilar o dado para cerca de $66 \%$ das bases pesquisadas. O bservaram-se os tipos de freqüência de atualização abaixo descritos:

- Tempo real: indica que os dados são atualizados em tempo real. G eralmente são bases de dados acessíveis via Internet ou outros sistemas em rede. 


\section{Beatriz Valadares C endón}

- D iária

- D iária (via Internet): indica que os dados são atualizados diariamente e podem ser acessados via Internet. N ormalmente, nesses casos, existe uma base de dados correspondente em CD-ROM que é publicada com uma freqüência menor.

\section{- Quinzenal}

\section{- Mensal}

\section{- Bimestral}

\section{- Trimestral}

\section{- Semestral}

\section{- Anual}

- Irregular: indica que não existe um padrão regular para atualização dos dados.

- E dições consecutivas: indica que os dados são atualizados, mas sem freqüência definida. Foram classificadas dentro de Edições Consecutivas, bases de dados que consistem do texto completo de livros ou obras de referência para os quais um novo CD -ROM élançado apenas quando surgeuma nova edição da obra.

- Variada: indica que existe mais de uma base de dados eque elas são atualizadas com freqüência diversificada.

A tabela 11 mostra como as bases de dados se distribuem entreessas categorias.

Como pode ser observado na tabela 11 , no caso das bases jurídicas, a soma totaliza número maior que 0 número total de bases. A razão é queas bases podem ser disponibilizadas em mais de um suporte, ecada suporte pode ter uma freqüência de atualização diferente. Por exemplo, uma base pode ser oferecida em CD-ROM e via Internet. A versão no CD-ROM é atualizada semestralmente, por exemplo, enquanto a versão na Internet éatualizada diariamente (útil no caso de diários oficiais, por exemplo). 0 utras combinações são, por exemplo, uma versão anual em CD -ROM euma mensal em disquete. Chama atenção o grande número de bases dedados atualizadas diariamente. Tal dado deve-se, talvez, à forma de coleta de dados desta pesquisa que privilegiou bases oferecidas via I nternet.
TABELA 11

Bases de dados por freqüência de atualização

\begin{tabular}{|c|c|c|c|c|c|c|}
\hline \multirow[b]{2}{*}{ Freqüência } & \multicolumn{2}{|c|}{ Bases juridicas } & \multicolumn{2}{|c|}{ Outras áreas } & \multicolumn{2}{|c|}{ Total } \\
\hline & $\begin{array}{c}\text { Quant. } \\
\text { Total }\end{array}$ & $\begin{array}{c}\% \text { (sobre } \\
86)\end{array}$ & $\begin{array}{l}\text { Quant. } \\
\text { Total }\end{array}$ & $\begin{array}{c}\% \text { (sobre } \\
48)\end{array}$ & $\begin{array}{l}\text { Quant. } \\
\text { Total }\end{array}$ & $\begin{array}{c}\% \text { (sobre } \\
134)\end{array}$ \\
\hline Diária & 28 & $33 \%$ & 13 & $27 \%$ & 41 & $31 \%$ \\
\hline Semanal & 8 & $9 \%$ & 1 & $2 \%$ & 9 & $7 \%$ \\
\hline Quinzenal & 1 & $1 \%$ & 0 & $0 \%$ & 1 & $1 \%$ \\
\hline Mensal & 8 & $9 \%$ & 2 & $4 \%$ & 10 & $7 \%$ \\
\hline Bimestral & 9 & $10 \%$ & 0 & $0 \%$ & 9 & $7 \%$ \\
\hline Trimestral & 13 & $15 \%$ & 0 & $0 \%$ & 13 & $10 \%$ \\
\hline jemestral & 2 & $2 \%$ & 0 & $0 \%$ & 2 & $1 \%$ \\
\hline Anual & 8 & $9 \%$ & 4 & $8 \%$ & 12 & $9 \%$ \\
\hline rregular & 1 & $1 \%$ & 2 & $4 \%$ & 3 & $2 \%$ \\
\hline $\begin{array}{l}\text { Edições } \\
\text { Consecutivas }\end{array}$ & 1 & $1 \%$ & 0 & $0 \%$ & 1 & $1 \%$ \\
\hline Variada & & $0 \%$ & 1 & $2 \%$ & 1 & $1 \%$ \\
\hline Tempo real & & $0 \%$ & 4 & $8 \%$ & 4 & $3 \%$ \\
\hline $\begin{array}{l}\text { Não } \\
\text { ornecida }\end{array}$ & 24 & $28 \%$ & 21 & $44 \%$ & 45 & $34 \%$ \\
\hline Total & 103 & & 48 & & 151 & \\
\hline
\end{tabular}

onte: elaborada pela autora.

o bservação: os dados totalizam mais de $100 \%$ porque as bases podem ser fornecidas em mais de uma modalidade.

\section{Os produtores das bases de dados}

Foram identificados 68 produtores de bases de dados distribuídos pelos estados brasileiros, conformemostrado na tabela 12, a seguir. São Paulo responde pela produção de $38 \%$ das bases identificadas, seguido de Rio de Janeiro eD istrito F ederal, ambos com $18 \%$. O s outros estados apresentam contribuições menos significativas, entre as bases levantadas nesta pesquisa.

A tabela 13 , a seguir, mostra que $65 \%$ dos produtores têm o domínio COM eapenas 19\% têm o domínio GOV, indicando que, pelo menos no que tange às bases de dados de informação para negócios, o setor privado tem assumido a sua produção, muitas vezes com fins lucrativos.

N a categoria Ó rgãos do governo, foram incluídos todos os produtores de domínio GOV. Essa contém uma coleção heterogênea de organizações, tais como fundações (por exemplo, Fundação Centro de Informações e Dados do Rio de Janeiro - Cide), autarquias ligadas a ministérios (por exemplo, Embratur), bancos ( por exemplo, Banco do N ordeste), órgãos ligados a planejamento (por exemplo, Instituto de Pesquisa E conômica A plicada - I pea), assembléias legislativas ou 
ministérios (por exemplo, M inistério do Trabalho e Emprego). Constituem 11\% dos produtores na área jurídica e $18 \%$ nas demais áreas. D estacam-sena área de informação estatística e indicadores econômicos, que produzem mais de $50 \%$ das bases. Ó rgãos do governo muitas vezes disponibilizam as bases gratuitamente, como, por exemplo, as bases de dados do IBG E, Caged, eRais. Essas bases são riquíssimas fontes de informação, contendo dados coletados para fins diversos, mas, talvez por serem gratuitas, não oferecem formas amigáveis de extração evisualização dos dados desejados.

O bservou-se uma variedade de produtores: órgãos do governo, instituições comerciais, editoras, empresas de informática, associações, empresas de consultoria, câmaras do comércio e outros. A tabela 14 apresenta uma tentativa de categorização das instituições produtoras, com base no nome da organização. O bservase que prevalecem empresas de informática (24\%), editoras (18\%), órgãos de apoio a empresas eindústrias (15\%), empresas de consultoria (12\%) eórgãos ligados ao governo (16\%).

As características dos produtores estão relacionadas com o tipo de bases de dados que produzem. Assim, muitas editoras jurídicas que comercializam bases de dados, como, por exemplo, Editora Síntese, Lex Editora eEditora Saraiva, estão colocando livros, revistas, dicionários e códigos, antes impressos, em versão eletrônica, muitas vezes com atualização via Internet. Editoras de páginas amarelas, como a OESP M ídia, ligada ao jornal O Estado de São Paulo, produzem bases de dados de diretórios de empresas e serviços. Ó rgãos de apoio a empresas e indústria, como a Confederação $\mathrm{N}$ acional da Indústria ( $\mathrm{CNI}$ ), Federação das I ndústrias do Estado de São Paulo (Fiesp), Serviço Brasileiro de Apoio às M icro ePequenas Empresas (Sebrae) e a Câmara Americana de Comércio (Amcham), produzem, principalmente, diretórios de empresas, bases de dados de oportunidade de negócios, bem como algumas bases bibliográficas deassuntos de interesse para negócios, tais como empreendedorismo ou educação profissional. No caso das bases de dados de oportunidades de negócios, como a Bolsa de $\mathrm{N}$ egócios produzida pelo S ebrae e Bolsa de N egócios Turísticos da Embratur, os dados são fornecidos pelas próprias empresas que se cadastram no site, o que pode resultar em baixa qualidade devido à falta de controlena entrada.

\section{TABELA 12}

Localização dos produtores de bases de dados

\begin{tabular}{lcr}
\hline Estado & Número de produtores & $\%$ \\
\hline SP & 26 & $38 \%$ \\
RJ & 12 & $18 \%$ \\
DF & 12 & $18 \%$ \\
MG & 4 & $6 \%$ \\
RGS & 3 & $4 \%$ \\
PB & 2 & $3 \%$ \\
SC & 1 & $1 \%$ \\
PR & 1 & $1 \%$ \\
PA & 1 & $1 \%$ \\
PE & 1 & $1 \%$ \\
ES & 1 & $1 \%$ \\
Não consta & 4 & $6 \%$ \\
Total & 68 & $100 \%$ \\
\hline
\end{tabular}

Fonte: elaborada pela autora.

\section{TABELA 13}

\section{Domínio dos produtores de bases de dados}

\begin{tabular}{lrr}
\hline Domínio & N & $\%$ \\
\hline COM & 44 & $65 \%$ \\
GOV & 13 & $19 \%$ \\
ORG & 6 & $9 \%$ \\
BR & 2 & $3 \%$ \\
INF & 1 & $1 \%$ \\
NET & 1 & $1 \%$ \\
N ão consta & 1 & $1 \%$ \\
Total & 68 & $100 \%$ \\
\hline Fonte: ena
\end{tabular}

Fonte: elaborada pela autora.

TABELA 14

Tipos de organizações produtoras de bases de dados

\begin{tabular}{|c|c|c|}
\hline Tipo de Organizaçå̆o & Número & $\%$ \\
\hline Empresas de informática & 16 & $24 \%$ \\
\hline Editoras & 12 & $18 \%$ \\
\hline $\begin{array}{l}\text { Congresso Nacional, Assembléias Legislativas, } \\
\text { Ministérios e outros órgāos ligados ao governo }\end{array}$ & 11 & $16 \%$ \\
\hline $\begin{array}{l}\text { Orgãos de apoio a empresas e indústrias } \\
\text { (confederaçốes, federaçōes, câmaras de comércio) }\end{array}$ & 10 & $15 \%$ \\
\hline Empresas de consultoria & 8 & $12 \%$ \\
\hline Associaçōes profissionais & 3 & $4 \%$ \\
\hline Jornais & 2 & $3 \%$ \\
\hline Fundaçōes & 2 & $3 \%$ \\
\hline Bolsas de valores & 2 & $3 \%$ \\
\hline Instituiçôes de ensino & 1 & $1 \%$ \\
\hline Sem informação & 1 & $1 \%$ \\
\hline Total & 68 & $100 \%$ \\
\hline
\end{tabular}

Fonte: elaborada pela autora. 


\section{Beatriz Valadares C endón}

A área jurídica, por ter características próprias, introduz algumas distorções nos números apresentados na tabela 14, como é mostrado na tabela 15. As categorias de empresas especializadas em informática e informática jurídica (37\%) e editoras (32\%), juntas, constituem $71 \%$ dos produtores debasesjurídicas. Entretanto, perfazem apenas $5 \%$ dos produtores de bases nas demais áreas. Excetuando a área jurídica, os mais importante produtores de bases de dados são as confederações e federações de indústria eórgãos de apoio à empresas (38\%), órgãos ligados ao governo (18\%) e empresas de consultoria, como D un and Bradstreet do Brasil, IBM EC, Serasa e CMA, (13\%).

$\mathrm{Na}$ área de informação financeira, $50 \%$ das bases são produzidas por empresas de consultoria. D estaca-se também o jornal financeiro $G$ azeta M ercantil, responsável pela produção de três importantes bases de dados nas categorias de investimentos, financeira e biográfica. O utro jornal, O Estado de São Paulo, também está representado entre os produtores, por meio da editora OESP M ídia, a ele vinculada.

U ma informação que seria interessante obter é o tipo de organização que produz as bases (seórgão público ou privado, com fins lucrativos ou não). Esta informação normalmente não está disponível na página do produtor, e os dados sobre esse aspecto estão incompletos devido ao grandenúmero de instituições que não responderam ao questionário. Coletar esse dado fica como sugestão para uma posterior atualização desta pesquisa.

\section{Bases de dados por início da produção}

Essa informação não consta em cerca de $50 \%$ das bases dedados, mas, como era dese esperar, os dados coletados indicam que a maior parte das bases teve início de produção nos anos 90 (tabela 16).

\section{Bases de dados por forma de disponibilização}

Inicialmente, esperava-se encontrar bases de dados disponibilizadas basicamente em CD-ROM ou via Internet. E ntretanto, foi encontrada uma variedade de modalidades de oferecimento dentro dessas duas grandes categorias, como se vêabaixo:

- CD-ROM (grátis com assinatura da revista): oS CD-ROM ssão enviados sem custo, uma vez queo usuário
TABELA 15

Tipos de organizações produtoras de bases de dados (comparação entre a área jurídica e demais áreas)

\begin{tabular}{|c|c|c|}
\hline \multirow[b]{2}{*}{ ipo de Organizaçӑо } & \multicolumn{2}{|c|}{ Percentual } \\
\hline & Area Juridica & Demais áreas \\
\hline Issocią̧бes profissionais & $8 \%$ & $0 \%$ \\
\hline impresas de informática & $37 \%$ & $5 \%$ \\
\hline inpresas de consultoria & $8 \%$ & $13 \%$ \\
\hline ditoras & $32 \%$ & $0 \%$ \\
\hline ornais & $0 \%$ & $10 \%$ \\
\hline $\begin{array}{l}\text { Orgắcs de apoio a empresas e indústrias } \\
\text { confederacōos, federacóes, câmaras de comércio) }\end{array}$ & $5 \%$ & $38 \%$ \\
\hline nstituiçōes de ensino & $0 \%$ & $3 \%$ \\
\hline undaçōes & $0 \%$ & $8 \%$ \\
\hline $\begin{array}{l}\text { Congresso nacional, assembléias legislativas, } \\
\text { ainistérios e outros órgâos ligados ao governo }\end{array}$ & $11 \%$ & $18 \%$ \\
\hline olsas de valores & $0 \%$ & $5 \%$ \\
\hline em informaçīo & $0 \%$ & $3 \%$ \\
\hline cotal & $100 \%$ & $100 \%$ \\
\hline
\end{tabular}

onte: elaborada pela autora.

TABELA 16

Bases de dados por início da produção

\begin{tabular}{|c|c|c|c|c|c|c|}
\hline \multirow[t]{2}{*}{ Período } & \multicolumn{2}{|c|}{ Juridica } & \multicolumn{2}{|c|}{ Demais áreas } & \multicolumn{2}{|c|}{ Todas as áreas } \\
\hline & $\mathrm{N}$ & $\%$ & $\mathrm{~N}$ & $\%$ & $\mathrm{~N}$ & $\%$ \\
\hline 40.59 & 0 & $0 \%$ & 1 & $2 \%$ & 1 & $1 \%$ \\
\hline 6069 & 2 & $2 \%$ & 0 & $0 \%$ & 2 & $1 \%$ \\
\hline $70-79$ & 2 & $2 \%$ & 1 & $2 \%$ & 3 & $2 \%$ \\
\hline $80-89$ & 4 & $5 \%$ & 4 & $8 \%$ & 8 & $6 \%$ \\
\hline 1990 & 0 & $0 \%$ & 0 & $0 \%$ & 0 & $0 \%$ \\
\hline 1991 & 4 & $5 \%$ & 0 & $0 \%$ & 4 & $3 \%$ \\
\hline 1992 & 5 & $6 \%$ & 3 & $6 \%$ & 8 & $6 \%$ \\
\hline 1993 & 12 & $14 \%$ & 0 & $0 \%$ & 12 & $9 \%$ \\
\hline 1994 & 5 & $6 \%$ & 1 & $2 \%$ & 6 & $4 \%$ \\
\hline 1995 & 6 & $7 \%$ & 4 & $8 \%$ & 10 & $7 \%$ \\
\hline 1996 & 5 & $6 \%$ & 0 & $0 \%$ & 5 & $4 \%$ \\
\hline 1997 & 8 & $9 \%$ & 0 & $0 \%$ & 8 & $6 \%$ \\
\hline 1998 & 0 & $0 \%$ & 0 & $0 \%$ & 0 & $0 \%$ \\
\hline 1999 & 0 & $0 \%$ & 1 & $2 \%$ & 1 & $1 \%$ \\
\hline 2000 & 0 & $0 \%$ & 0 & $0 \%$ & 0 & $0 \%$ \\
\hline 2001 & 0 & $0 \%$ & 1 & $2 \%$ & 1 & $1 \%$ \\
\hline Não fornecida & 33 & $38 \%$ & 32 & $68 \%$ & 65 & $49 \%$ \\
\hline Total & 86 & $100 \%$ & 48 & $100 \%$ & 134 & $100 \%$ \\
\hline
\end{tabular}

Fonte: elaborada pela autora. 
adquira outro produto ( $n a$ maioria das vezes, esse produto éa versão impressa do conteúdo do CD-ROM ).

- CD-ROM (assinatura): OS CD ROMS são adquiridos mediante assinatura dos mesmos por um período definido (anual, semestral ou outros).

- CD-ROM (avulso): os CD -ROM s podem ser comprados isoladamente, ou seja, não é necessário assinatura dos mesmos por um período definido.

- Internet (grátis - acesso total): a base de dados está disponível na Internet com acesso completo às informações.

- Internet (grátis - acesso limitado): a base de dados está disponível na Internet, porém o acesso aos dados érestrito. Por exemplo, podem ser disponibilizados via I nternet apenas os dados do último ano.

- Internet (assinatura): a base de dados está disponível na sua totalidade na Internet, porém o acesso requer uma senha de acesso eé pago.

- Internet (atualizações): a base de dados é normalmente fornecida em outros meios (por exemplo, CD - ROM ), e as atualizações mais recentes dos dados (em geral diárias) podem ser acessadas via I nternet.

- On-line: a base de dados pode ser acessada remotamente, via rede que não seja Internet.

- Via e-mail: a base de dados não é disponibilizada diretamente para os usuários e só pode ser acessada mediante envio dee-mail solicitando consulta.

- D isquete: a base de dados é fornecida em disquete.

- Cópia demonstrativa: existe cópia grátis para demonstração/marketing da base de dados.

- Via consultoria específica (avulso): a base de dados não é disponibilizada diretamente para os usuários esó pode ser acessada mediante contratação de serviços de consultoria do produtor da base.

- Via consultoria específica (assinatura): a base de dados não é disponibilizada diretamente para os usuários e só pode ser acessada mediante contratação de serviços de consultoria do produtor da base por um período determinado.

TABELA 17
Bases de dados por tipo de disponibilização

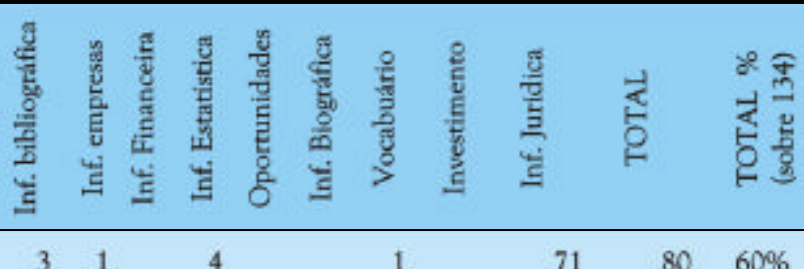

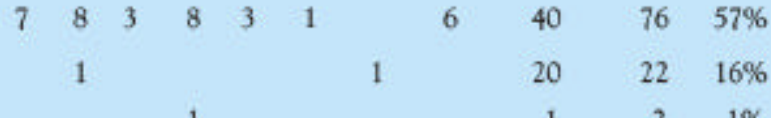

$1 \%$

$6 \%$

$1 \%$

$2 \%$

$1 \%$

$4 \%$

$1 \%$

$1 \%$

$\begin{array}{llllllllll}12 & 15 & 4 & 18 & 5 & 1 & 2 & 6 & 140 & 203\end{array}$

O bservação.: totalizam mais de $100 \%$ porque cada base de dados pode ser oferecida em mais de uma modalidade.

- Teleatendimento - grátis: a base de dados é disponível para consulta via solicitação por telefone.

- D isponível localmente: a base de dados é disponível para os usuários apenas nos recintos da empresa produtora/disponibilizadora

- Intranet: a base de dados é disponível na Intranet da empresa produtora.

A tabela 17 mostra o número de bases em cada grande grupo.

Conforme observado no rodapé da tabela 17, os números totalizam mais de $100 \%$, já que as bases de dados podem ser oferecidas em mais de uma modalidade. Cerca de $60 \%$ das bases de dados são disponibilizadas em CD ROM e $57 \%$ via Internet, modalidadeque deve continuar ganhando espaço. Surpreende a quantidade de bases (16\%) fornecidas via disquete na área jurídica e o baixo fornecimento de cópias demonstrativas. As demais modalidades de oferecimento não são expressivas.

$\mathrm{N}$ a tabela 18, a seguir, observa-se uma tendência de fornecimento via CD-ROM na área jurídica (83\%), enquanto nas demais áreas $75 \%$ das bases são fornecidas via Internet. 


\section{Beatriz Valadares C endón}

TABELA 18

\section{Tipo de disponibilização por categoria de informação}

\begin{tabular}{|c|c|c|c|c|c|c|}
\hline & \multicolumn{2}{|c|}{ Juridica } & \multicolumn{2}{|c|}{ Demais áreas } & \multicolumn{2}{|c|}{ Todas as áreas } \\
\hline & $\mathrm{N}$ & $\%$ & $\mathrm{~N}$ & $\%$ & $\mathrm{~N}$ & $\%$ \\
\hline CD ROM & 71 & $83 \%$ & 9 & $19 \%$ & 80 & $60 \%$ \\
\hline Internet & 40 & $47 \%$ & 36 & $75 \%$ & 76 & $57 \%$ \\
\hline Disquete & 20 & $23 \%$ & 2 & $4 \%$ & 22 & $16 \%$ \\
\hline Copia demonstrativa & 1 & $1 \%$ & 1 & $2 \%$ & 2 & $1 \%$ \\
\hline Consultoria & 2 & $2 \%$ & 6 & $13 \%$ & 8 & $6 \%$ \\
\hline Teleatendimento & & $0 \%$ & 2 & $4 \%$ & 2 & $1 \%$ \\
\hline On-line & 1 & $1 \%$ & 2 & $4 \%$ & 3 & $2 \%$ \\
\hline E-mail & & $0 \%$ & 1 & $2 \%$ & 1 & $1 \%$ \\
\hline Disponivel no local & 3 & $3 \%$ & 3 & $6 \%$ & 6 & $4 \%$ \\
\hline Intranet & 1 & $1 \%$ & 1 & $2 \%$ & 2 & $1 \%$ \\
\hline Impresso & 1 & $1 \%$ & 0 & $0 \%$ & 1 & $1 \%$ \\
\hline TOTAL & 140 & & 63 & & 203 & \\
\hline
\end{tabular}

Fonte: elaborada pela autora.

O bservação.: totalizam mais de $100 \%$ porque cada base de dados pode ser oferecida em mais de uma modalidade.

TABELA 19

Oferecimento via Internet

\begin{tabular}{|c|c|c|c|c|c|c|c|c|c|c|c|c|c|c|}
\hline & \multirow{2}{*}{ 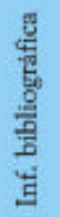 } & \multirow[b]{2}{*}{ 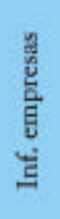 } & \multirow[b]{2}{*}{ 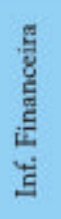 } & \multirow[b]{2}{*}{ 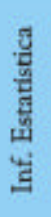 } & \multirow{2}{*}{ 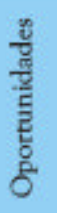 } & \multirow{2}{*}{ 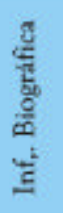 } & \multirow[b]{2}{*}{ 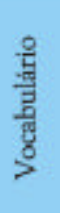 } & \multirow[b]{2}{*}{ 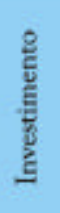 } & \multicolumn{2}{|c|}{ Juridica } & \multicolumn{2}{|c|}{ Demais áreas } & \multicolumn{2}{|c|}{ Todas as áreas } \\
\hline & & & & & & & & & $\mathrm{N}$ & $\%$ & $\mathrm{~N}$ & $\%$ & $\mathrm{~N}$ & $\%$ \\
\hline $\begin{array}{l}\text { Internet (sem } \\
\text { especificaçäo) }\end{array}$ & & & 1 & & 3 & & & & 1 & $24 \%$ & 4 & $8 \%$ & 5 & $4 \%$ \\
\hline $\begin{array}{l}\text { Internet (grátis- } \\
\text { acesso total) }\end{array}$ & 4 & 7 & 2 & 4 & & 1 & & 2 & 14 & $1 \%$ & 20 & $42 \%$ & 34 & $25 \%$ \\
\hline $\begin{array}{l}\text { Internet (grátis - } \\
\text { acesso limitado) }\end{array}$ & 3 & & & 3 & & & & 2 & 3 & $15 \%$ & 8 & $17 \%$ & 11 & $8 \%$ \\
\hline $\begin{array}{l}\text { Internet } \\
\text { (assinatura) }\end{array}$ & & 1 & & 1 & & & & 2 & 18 & $5 \%$ & 4 & $8 \%$ & 22 & $16 \%$ \\
\hline $\begin{array}{l}\text { Internet } \\
\text { (atualizą̧̄oses) }\end{array}$ & & & & & & & & & 4 & $21 \%$ & 0 & $0 \%$ & 4 & $3 \%$ \\
\hline $\begin{array}{l}\text { Cópia } \\
\text { (demonstrativa) }\end{array}$ & & & & 1 & & & & & 1 & $5 \%$ & 1 & $2 \%$ & 2 & $1 \%$ \\
\hline
\end{tabular}

Fonte: elaborada pela autora.

A tabela 19 apresenta os dados detalhados para as diversas modalidades de oferecimento via Internet. Somando-se acesso total e acesso parcial, 33\% do total das bases de dados são oferecidos gratuitamente via I nternet, sendo que, na área jurídica, apenas $16 \%$ são grátis. $N$ as demais áreas, essa porcentagem sobepara 59\%. São responsáveis por esses altos índices as bases de dados de informação bibliográfica, estatísticas e diretórios de empresa. 


\section{Bases de dados por cobertura geográfica}

Como mostrado na tabela $20,77 \%$ das bases de dados em todas as categorias, exceto a jurídica, possuem cobertura nacional. M erecem destaque também bases com cobertura estadual (17\%) e internacional (15\%). Esse dado não foi apresentado para a área jurídica já que $76 \%$ das bases não apresentaram essa informação. $\mathrm{Na}$ tabela 20 , os dados somam mais que $100 \%$, pois algumas bases são de cobertura nacional e internacional.

\section{CONSIDERAÇÕES FINAIS}

0 diretório de bases de dados de informação para negócios, desenvolvido através desta pesquisa, soma-se a outros esforços originados na Escola de Ciência da I nformação da U FM G (M ontalli, 1994; Barbosa, 1994; Souza \& Borges, 1996; Souza, 1996; Borges\& Campello, 1997; Borges \& Carvalho, 1998; Souza \& Borges, 1999; D uarte, 2000; Cendón, 2002) que tiveram o intuito de melhor conhecer a produção das informações para negócios por organizações privadas e governamentais. D evido à metodologia adotada, o diretório não é exaustivo. R eflete as bases de dados mais freqüentemente referenciadas em páginas da Internet ou cujos produtores são citados em textos da literatura sobre informação para negócio. A falta de padronização da terminologia na Internet contribuiu para a dificuldade de se localizarem as bases. Por exemplo, nos sites apareciam termos e expressões como "bolsa de negócios" ou "cadastro de empresas" em vez de base de dados de empresas. O bservou-se ainda que, outras vezes, o site da organização produtora não mencionava a base de dados propriamente, mas os serviços dela derivados. Ressalte-se também o dinamismo do setor: as informações nos sites podiam mudar rapidamente, novas bases de dados apareciam, sites eram reestruturados, saíam do ar, informação sobre as bases dedados desapareciam. Supõe-se, conseqüentemente, que existam muitas outras bases de dados não divulgadas na época da pesquisa ou que não apareçam nos sites com tal designação.

Apesar de todas essas dificuldades, a pesquisa revelou um número relativamente expressivo de bases. Assim como as descrições sobre as bases de dados na I nternet eram, muitas vezes, insuficientes para o potencial usuário determinar sua utilidade, na maior parte das vezes sua documentação, que revelaria seu escopo, conteúdo e forma deutilização, é pobre ou inexistente. Embora não se tenha analisado extensivamente detalhes das interfaces ou recursos de busca oferecidos, pode-se afirmar, de maneira genérica, que a maioria não era dirigida para os profissionais da informação. 0 mercado é voltado para o usuário final, com interfaces simplificadas e pontos de acesso limitados. Estão, como pode ser visto, disponibilizadas de forma dispersa. Seria interessante que existisse no Brasil uma empresa distribuidora de bases de dados, nos moldes do D ialog, que comprasse as bases de dados, disponibilizasse as mesmas por meio de sistema unificado de acesso e busca e as divulgasse mais amplamente, permitindo assim que uma comunidade maior se beneficiasse das informações que estão sendo coletadas e organizadas.

É desejável queo diretório resultante desta pesquisa possa ser um embrião para a criação de uma obra de referência, atualizada, com periodicidade regular, e abrangente, incluindo não só um número maior de produtores esuas bases de dados, como também mais informações sobre esses. Exemplos de outros dados interessantes de serem compilados: caracterização mais aprofundadas das empresas produtoras, como seu tamanho, tempo deatuação no mercado efaturamento; software utilizado na produção das bases de dados; serviços e produtos de informação gerados a partir das bases de dados.

A rtigo recebido em 17-03-2003 e aceito para publicação em 27-03-2003 


\section{Beatriz Valadares C endón}

\section{REFERÊ N CIAS}

BARBOSA, Ricardo Rodrigues. Informação para negócios no Brasil. In: SEM INARIO NACIONAL DE INFORM ACAO PARA INDUSTRIAE COMERCIO EXTERIOR, 1., 1993, Belo H orizonte. Anais... Belo H orizonte: UFM G,EB, 1994.241 p.

BARRETO, Auta Rojas. A informação eficaz na empresa. Ciência da Informação, Brasília, v. 20, n. 1, p. 78-81, jan./jun. 1991.

. Informação empresarial para o M ercosul: a expansão das fronteiras das microempresas. Ciência da Informação, Brasília, v. 25, n. 1, p. 144-149, jan./ abr. 1996.

BO RGES, M ônica Erichsen N assif; CAM PELLO, BernadeteSantos. A organização da informação para negócios no Brasil. Perspectivas em Ciência da Informação, Belo H orizonte, v. 2, n. 2, p. 149-161, jul./ dez., 1997.

; CARVAL HO , N atália Guiné de M ello. Produtos e serviços de informação para negócios no Brasil: características. Ciência da Informação, Brasília, v. 27, n. 1, p. 76-80, jan./abr. 1998.

CEN D Ó N, Beatriz Valadares. Bases de dados de informação para negócios. Ciência da Informação, Brasília, v. 31, n. 2, p. 30-43, maio./ ago., 2002.

DUARTE, Luiz O távio Borges. Informação para negócios na I nternet: estudo das necessidades informacionais da indústria moveleira de $M$ inas $G$ erais. Perspectivas em Ciência da Informação, Belo H orizonte, v. 5, n. 1, p. 23-40, jan./jun., 2000.

JAN UZZI, CelesteA. Sirotheau Correa; M ONTALLI, Kátia M aria Lemos. Informação tecnológica epara negóciosno Brasil: introdução a uma discussão conceitual. Ciência da Informação, Brasília, v. 28, n. 1, p. 28-36, jan./ abr., 1999.

FIGUEIRED O, N ice. Informação para negócios: um novo desafio. In: CONGRESSO LATINO-AMERICANO DE BIBLIOTECONOMIA E DOCUM ENTACAO, 2., 1994, Belo H orizonte. Anais... Belo H orizonte: ABM G, 1994.820 p.
LAVIN, M ichael R. Business information: how to find it, how to use it. Phoenix, Arizona: Oryx, 1992.

M ARCACCIO, Kathleen Young. Gale directory of databases. D etroit :G ale Research, 1994. $2 \mathrm{v}$

M ONTALLI, Kátia. Informação para negócios no Brasil: reflexões. In: SEM INÁRIO NACIONAL DE INFORM ACAO PARA INDÚSTRIAE COMERCIO EXTERIOR, 1., 1993, Belo H orizonte. Anais... Belo H orizonte: UFM G, EB, 1994. $241 \mathrm{p}$.

. Informação para negócios: discussão. In: SEM INARIO NACIO N AL DE INFORM AÇÃO PARA IN DÚ STRIA E COMÉRCIO EXTERIOR, 1., 1993, Belo H orizonte. Anais... Belo H orizonte: UFM G, EB, 1994. 241 p.

PINTO, Virgínia Bentes. Informação para a indústria: algumas considerações. In: CONGRESSO LATINO-AM ERICANO DE BIBLIOTECONOMIAE D OCU M EN TAÇÃO, 2., 1994, Belo H orizonte. Anais... Belo H orizonte: ABM G, 1994. $820 \mathrm{p}$.

SOUZA, Terezinha deFátima Carvalho de. O rganização da área de informação para negócios no Brasil: a questão da informação financeira esuas fontes. Belo H orizonte: UFM G, EB, 1996. (Projeto deD issertação).

; BO RGES, M ônica Erichsen N assif. Fontes de informação financeira no Brasil. Ciência da Informação, Braślia, v. 28, n. 1, p. 37-48, jan./abr. 1999. Instituições provedoras de informação tecnológica no Brasil: analise do potencial para atuação com informação para negócios. Ciência da Informação, Brasília, v. 25, n. 1, p. 52-58, jan./abr. 1996. 